\title{
Does money matter? A deterministic model with cash-in-advance constraints in factor markets*
}

\author{
Erdem Başç ${ }^{1}$ and İsmail Sağlam ${ }^{2}$ \\ ${ }^{1}$ Department of Economics, Bilkent University, Bilkent, Ankara 06533, Turkey \\ 2 Department of Economics, Princeton University, Princeton, NJ 08544-1021, \\ U.S.A.
}

\begin{abstract}
This paper points to the importance of finance constraints in affecting competitive outcomes in economies that operate with money. We study a simple dynamic economy that operates through the use of fiat money under cash-in-advance constraints in all markets. We assume that the labor market opens before the goods market and the total money stock changes at a constant rate.

After describing the economy, we define and characterize its stationary monetary competitive equilibria (SMCE). In all cases where SMCE exist, the real wage is observed to be below the marginal product of labor and negatively related to the money growth rate, leaving positive pure profits to the firms. Only under Friedman's optimal money supply rule, zero pure profits are obtained.

Neutrality of money is also studied in this context. In cases where the SMCE is unique, the equilibrium is Pareto efficient and money is neutral. In the case of continuum of equilibria and under sticky wages, which is consistent with market clearing in this model, the level of money stock can affect levels of output, employment, and welfare.
\end{abstract}

JEL Classification Numbers: D52, D9, E41

Keywords: Cash-in-advance, labor markets, neutrality of money

\footnotetext{
*The second author gratefully acknowledges the hospitality of the Economics Departments of the University of Michigan and Princeton University, the grant awarded by the Scientific and Technical Research Council of Turkey (TUBITAK) in scope of the NATO Science Fellowship Programme, supports from Bilkent University and from the Center for Economic Design of Bog̃aziçi University. A previous version has been presented at the III. International Conference on Economic Theory and Applications, Antalya, June 1997, and at Bilkent and Bog̃aziçi Universities. We are in particular grateful to Selahattin Imrohorog̃lu, Ivan Pastine, Subidey Togan and especially an anonymous referee for their useful comments.
} 


\section{Introduction}

Classical results such as Pareto efficiency of competitive equilibrium, sweeping out of pure profits in case of constant returns production technologies, and real wage of a worker being equated to its marginal product have all been derived under the assumption that the market structure is complete. Such a structure would prevail if either the commodity markets (Debreu, 1959, Chapter 7), or the security markets are complete (Arrow, 1964). Under either institutional arrangement there is no role to be played by fiat money. Even if the government were to create such outside money, its market value would be zero.

One way of introducing valued fiat money in a model would be to impose the requirement that at least for some goods no purchase is possible without a specific piece of paper, and that the time horizon is infinite. The use of such cash-in-advance constraints in macroeconomic models was proposed by Clower (1967) and was popularized especially with the papers by Lucas $(1980,1984,1990)$ and Lucas and Stokey $(1983,1987)$. In these papers, cash-in-advance constraints are imposed on the consumers' purchases of a subset of commodities or assets. However the firm, an artificial entity which has a constant returns production function, does not face any cash constraint. So the interpretation would be that they sell their to-be-produced goods in return for cash to consumers and pay the wage and rental bills (partially) with this money. In that case, the classical result of zero pure profits with marginal products being equal to factor returns follows. An exception is a paper by Fuerst (1992) where cash-in-advance constraints are imposed on all transactions. Fuerst (1992), following Lucas (1990), considers a stochastic model with representative gigantic families, members of which share the same objective of maximizing family welfare. A firm is a part of the family and has access to money markets to borrow their cash needs for the puchase of labor services. As a result, a deviation of real wages from marginal product of labor takes place.

In contrast, we study a much simpler deterministic model but with two different types of agents who do not cooperate. We too observe a deviation of the equilibrium real wage from the marginal product of labor. This observation points to the importance of sequencing of transactions and the corresponding nature of the cash-in-advance constraints. We assume that first the factor markets and then the commodity markets open. In such an environment, producers face a cash-in-advance constraint in their factor payments. Money needed by producers here could be interpreted as working capital. After the factor payments are made, the commodity markets open and the factor income can be spent here, again under a cash-in-advance constraint. This minor change in the sequencing of transactions is shown to have an important effect on the equilibrium prices. For typical parameter values, real rental rate for the single factor that is subject to a cash constraint turns out to be strictly below its marginal product. This gap is 
observed to widen as the money growth rate is increased. Therefore, in this model we observe (pure) income distribution effects of inflation.

Also, under a very special case, a continuum of equilibria which can be Pareto ranked is shown to exist. In such a case, non-neutrality of the level of money stock itself becomes a possibility, despite the fact that we have a deterministic model with perfect foresight individual optimization and market clearing.

Section 2 introduces the details of the simplest possible model we could think of, to capture the setting described above. Section 3 characterizes the set of equilibria for various parameter values on technology and preferences. The final section concludes by making connections to the literature on the optimal money supply rule.

\section{The model}

We consider an economy in which there are two commodities at each time $t$, labor $L_{t}$ and a nonstorable consumption good (apple) $q_{t}$. There are two types of agents indexed by $i=1,2$. Neither one values leisure,${ }^{1}$ and their preferences over the lifetime consumption are the same and given by $\sum_{t=0}^{\infty} \beta^{t} U\left(c_{i t}\right)$, where $\beta \in(0,1)$ is the common discount factor, $c_{i t}$ is the consumption of agent $i$ at time $t$ and $U($.$) is the common utility function for$ both agents showing the instantaneous satisfaction derived from consuming apples at each time. We assume that $U$ is twice continuously differentiable, $U^{\prime}()>$.0 and $U^{\prime \prime}()<$.0 .

Agent 1 has a labor endowment $\bar{L}$ and a constant returns technology $f_{1}(L)=L$ to convert labor into apples with marginal product of labor equal to one. Agent 2 has no labor endowment, but a better technology $f_{2}(L)=\gamma L$ which is also constant returns to scale with marginal product of labor greater than one $(\gamma>1)$. Other than these production possibilities, there are no endowment of apples.

We assume that real wage contracts that promise delivery of apples after the harvest are not enforceable. Therefore the economy operates with money under cash-in-advance constraints in both labor and apple markets. Money is perfectly storable and $M_{i, t}$ denotes the money holding of agent $i$ at time $t$. We assume that initially all currency in the economy, $M$, is owned by agent 2 , that is, $M_{1,0}=0$ and $M_{2,0}=M{ }^{2}$

The total currency in the economy that we denote by $M_{t}$ is assumed to

\footnotetext{
${ }^{1}$ Since leisure does not enter the utility function, the factor of production in the model could, perhaps, be better interpreted as, for example, water (for irrigation) or even bees (for pollination). We thank an anonymous referee for suggesting these interpretations.

${ }^{2}$ Stokey and Lucas with Prescott (1989, Exercise 5.17) indicate that even if initial money stock were not zero, after a finite number of periods, our agent 1 would choose to run it down to zero. This would be the case whenever the gross real return from savings is low compared to the gross rate of time preference $1 / \beta$.
} 
be altered every period by the government at a constant rate $\theta>-1$ so that for all $t$

$$
M_{t+1}=(1+\theta) M_{t} .
$$

Now let $w_{t}$ and $p_{t}$, respectively, denote the money wage rate and the price of apples at time $t$.

The timing of transactions is as follows: Agent $i$ starts period $t$ with $M_{i, t}$ units of currency. Then government transfers agent 2 by paying him $\theta M_{t}$ units of currency (Note here that government taxes agent 2 when $\theta<0$ ). We assume that agent 2 regards this transfer as given and not as a function of his initial money balances. ${ }^{3}$ First the labor market opens where labor can be sold (by agent 1 to agent 2 due to the endowment structure) in return for money. Then apple production takes place with the purchased labor. After the harvest of apples, goods market opens where apple can be sold (normally by agent 2 to agent 1 for earning money to be used next period) for money.

Given the endowment structure described above, and the prices $\left\langle w_{t}, p_{t}\right\rangle_{t=0}^{\infty}$, we can write the infinite-horizon utility maximization problems of the two agents as follows:

Agent 1

$$
\begin{gathered}
\text { (P1) } \quad \max \sum_{t=0}^{\infty} \beta^{t} U\left(c_{1, t}\right) \\
\text { subject to, for all } t \\
c_{1, t}=\left(\bar{L}-L_{t}^{s}\right)+q_{t}^{d}, \\
L_{t}^{s} \leq \bar{L}, \\
M_{1, t+1}=M_{1, t}+w_{t} L_{t}^{s}-p_{t} q_{t}^{d}, \\
M_{1, t}, c_{1, t}, q_{t}^{d}, L_{t}^{s} \geq 0, \text { and } \\
M_{1,0}=0 \text { is given. }
\end{gathered}
$$

$\underline{\text { Agent } 2}$

$$
\begin{gathered}
(P 2) \quad \max \sum_{t=0}^{\infty} \beta^{t} U\left(c_{2, t}\right) \\
\text { subject to, for all } t \\
c_{2, t}=\gamma L_{t}^{d}-q_{t}^{s}, \\
w_{t} L_{t}^{d} \leq M_{2, t}+\theta M_{t}, \\
M_{2, t+1}=M_{2, t}+\theta M_{t}-w_{t} L_{t}^{d}+p_{t} q_{t}^{s},
\end{gathered}
$$

\footnotetext{
${ }^{3}$ This assumption makes full sense only when there is a large number of agents in the economy, and when the government follows a lump-sum distribution policy, rather than a proportional one.
} 


$$
\begin{gathered}
M_{2, t}, c_{2, t}, q_{t}^{s}, L_{t}^{d} \geq 0, \text { and } \\
M_{2,0}=M \quad \text { is given } .
\end{gathered}
$$

The cash-in-advance constraint of agent 2 is present in its labor market transactions and is given by the second constraint in $(P 2)$. For agent 1 , the non-negativity requirement for $M_{1, t}$, together with the third constraint in $(P 1)$, is in effect a cash-in-advance constraint on apple purchases.

We will assume that there are large and equal numbers of each type of agents and hence be concerned with monetary competitive equilibrium (MCE). Under the aforementioned assumption that initially all currency in the economy is owned by agent 2 (the entrepreneur), MCE consists of an infinite sequence of apple prices, money wages, labor demands, labor supplies, apple demands, apple supplies and money holdings by the two agents such that at each date demands, supplies and money holdings are optimal under the given wage and price sequences, demand equals supply in both labor and apple markets, and money holdings sum up to the total money supply at each time.

Formally, we say that $\left\langle p_{t}, w_{t}, L_{t}^{d}, L_{t}^{s}, q_{t}^{d}, q_{t}^{s}, M_{1, t}, M_{2, t}\right\rangle_{t=0}^{\infty}$ is a MCE if

(i) $\left\langle L_{t}^{s}, q_{t}^{d}, M_{1, t}\right\rangle_{t=0}^{\infty}$ solves $(P 1)$ and $\left\langle L_{t}^{d}, q_{t}^{s}, M_{2, t}\right\rangle_{t=0}^{\infty}$ solves $(P 2)$

$$
\text { under }\left\langle w_{t}, p_{t}\right\rangle_{t=0}^{\infty} \text {, }
$$

(ii) $L_{t}^{d}=L_{t}^{s}$ and $q_{t}^{d}=q_{t}^{s}$, for all $t$, and

(iii) $M_{1, t}+M_{2, t}=M_{t} \equiv(1+\theta)^{t} M$, for all $t$.

In addition to the MCE concept, we define the stationary monetary competitive equilibrium (SMCE), where the prices, wages, demands, supplies, money holdings are consistent with dynamic optimization and market clearing, and also satisfy for all $t$;

(i) $p_{t+1} / p_{t}=w_{t+1} / w_{t}=M_{i, t+1} / M_{i, t}=(1+\theta)$ for all $i$, and

(ii) $L_{t+1}^{s} / L_{t}^{s}=L_{t+1}^{d} / L_{t}^{d}=q_{t+1}^{s} / q_{t}^{s}=q_{t+1}^{d} / q_{t}^{d}=1$.

In the rest of the paper we will try to characterize the set of SMCE.

\section{Results}

In both $(P 1)$ and $(P 2)$, we first eliminate the equality constraints by substituting for $c_{1, t}, q_{t}^{d}$ and $c_{2, t}, q_{t}^{s}$, respectively. Now, based on the observation that only contemporaneous values of $L_{t}$ appear in the instantaneous utility function at all times, it is straightforward to obtain labor demand and supply as a function of real wage as shown in Figure 1.

If at any time $t$ the real wage $w_{t} / p_{t}$ is less than $\gamma$, agent 2 will spend all of his money on purchasing labor so that the cash-in-advance (CIA) constraint will be binding. If $w_{t} / p_{t}=\gamma$, labor demanded by agent 2 will be between zero and $\left(M_{2, t}+\theta M_{t}\right) / p_{t}$. If $w_{t} / p_{t}>\gamma$, labor demanded will be zero. 


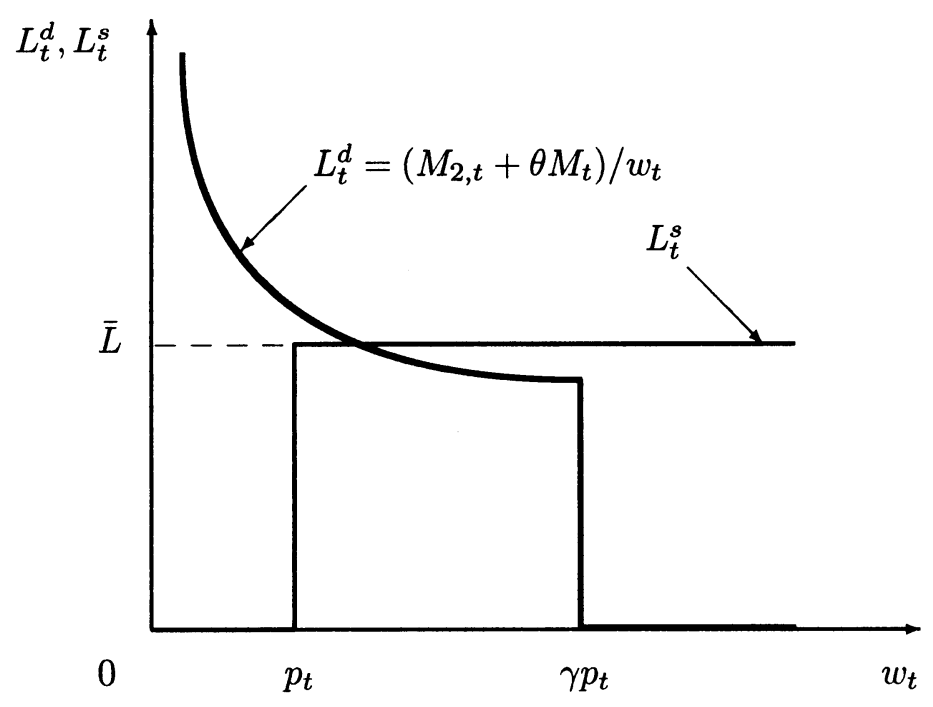

FIGURE 1. Labor supply and demand functions for a given $p_{t}$ and $M_{2, t}$.

So the labor demand function will be

$$
L_{t}^{d}\left(w_{t} / p_{t}\right)= \begin{cases}\left(M_{2, t}+\theta M_{t}\right) / w_{t} & \text { if } w_{t} / p_{t}<\gamma \\ \in\left[0,\left(M_{2, t}+\theta M_{t}\right) / w_{t}\right] & \text { if } w_{t} / p_{t}=\gamma \\ 0 & \text { otherwise }\end{cases}
$$

For agent 1 , the comparison of real wage is with his own marginal product, which is 1 . If at any time $t$ the real wage $w_{t} / p_{t}$ is higher than 1 , he will supply $\bar{L}$, if equal to 1 he will be indifferent between 0 and $\bar{L}$ and if less than 1 he will supply zero labor. The labor supply function can then be written as

$$
L_{t}^{s}\left(w_{t} / p_{t}\right)= \begin{cases}\bar{L} & \text { if } w_{t} / p_{t}>1 \\ \in[0, \bar{L}] & \text { if } w_{t} / p_{t}=1 \\ 0 & \text { otherwise. }\end{cases}
$$

The following proposition characterizes stationary monetary competitive equilibrium over the parameter space of $(\beta, \gamma, \theta)$.

Proposition 1 Assume that $\beta<(1+\theta)$. There exists a $S M C E$ if and only if $\beta \gamma \geq 1+\theta$ and is given by (3)-(7) for each $t$ : 


$$
\begin{gathered}
w_{t}=\left\{\begin{array}{cc}
M_{t+1} / \bar{L} & \text { if } \beta \gamma>1+\theta \\
(1+\theta)^{t} \bar{w} \in\left[M_{t+1} / \bar{L}, \infty\right) & \text { if } \beta \gamma=1+\theta
\end{array}\right. \\
p_{t}=\frac{(1+\theta) w_{t}}{\beta \gamma}, \\
L_{t}^{d}=L_{t}^{s}=M_{t+1} / w_{t} \\
q_{t}^{d}=q_{t}^{s}=M_{t+1} / p_{t} \\
M_{1, t}=0, \quad M_{2, t}=M_{t} \equiv(1+\theta)^{t} M
\end{gathered}
$$

Proof. We observe that if any two of the money, labor and apple markets clear, then the third one will also clear. This follows from the third equality constraints in both $(P 1)$ and $(P 2)$. Therefore, we can eliminate $q_{t}^{d}$ and $q_{t}^{s}$ in the problems $(P 1)$ and $(P 2)$, respectively. Similarly, eliminating $c_{1, t}$ and $c_{2, t}$ in $(P 1)$ and $(P 2)$, respectively, as well and rewriting the inequality constraints accordingly, we obtain

$$
\begin{aligned}
& \left(P 1^{\prime}\right) \quad \max \sum_{t=0}^{\infty} \beta^{t} U\left(\bar{L}+\left(\frac{w_{t}}{p_{t}}-1\right) L_{t}^{s}+\frac{1}{p_{t}}\left(M_{1, t}-M_{1, t+1}\right)\right) \\
& \text { subject to, for all } t \text {, } \\
& \bar{L}+\left(\frac{w_{t}}{p_{t}}-1\right) L_{t}^{s}+\frac{1}{p_{t}}\left(M_{1, t}-M_{1, t+1}\right) \geq 0, \\
& L_{t}^{s} \leq \bar{L}, \\
& M_{1, t+1} \leq M_{1, t}+w_{t} L_{t}^{s}, \\
& M_{1, t}, L_{t}^{s} \geq 0, \text { and } \\
& M_{1,0}=0 \text {. } \\
& \left(P 2^{\prime}\right) \quad \max \sum_{t=0}^{\infty} \beta^{t} U\left(\left(\gamma-\frac{w_{t}}{p_{t}}\right) L_{t}^{d}+\frac{1}{p_{t}}\left(M_{2, t}+\theta M_{t}-M_{2, t+1}\right)\right) \\
& \text { subject to, for all } t \text {, } \\
& \left(\gamma-\frac{w_{t}}{p_{t}}\right) L_{t}^{d}+\frac{1}{p_{t}}\left(M_{2, t}+\theta M_{t}-M_{2, t+1}\right) \geq 0, \\
& M_{2, t+1} \geq M_{2, t}+\theta M_{t}-w_{t} L_{t}^{d}, \\
& w_{t} L_{t}^{d} \leq M_{2, t}+\theta M_{t}, \\
& M_{2, t}, L_{t}^{d} \geq 0 \text {, and } \\
& M_{2,0}=M \text {. }
\end{aligned}
$$


For money market clearing, we must have $M_{2, t}=M_{t} \equiv(1+\theta)^{t} M$ in SMCE since $M_{1, t}=0$ for all $t$. Let us show that such a money holding plan is optimal for agent 2 .

First note that (1) and (2) imply that the labor market is in equilibrium only if $1 \leq w_{t} / p_{t} \leq \gamma$.

We will first show there is no SMCE with $w_{t} / p_{t}=\gamma$. To see this, insert $w_{t} / p_{t}=\gamma$ into the objective function of $\left(P 2^{\prime}\right)$ to obtain

$$
\max \sum_{t=0}^{\infty} \beta^{t} U\left(\frac{1}{p_{t}}\left(M_{2, t}+\theta M_{t}-M_{2, t+1}\right)\right) .
$$

The Euler equation for agent 2, associated with control $\left(1 / p_{t}\right) M_{2, t+1}$, is given by

$$
U^{\prime}\left(c_{2, t}\right)=\beta \frac{p_{t}}{p_{t+1}} U^{\prime}\left(c_{2, t+1}\right), \text { for all } t .
$$

At a stationary equilibrium, $c_{2, t+1}=c_{2, t}$ for all $t$. Since $U^{\prime}()>$.0 and $\beta p_{t} / p_{t+1}=\beta /(1+\theta)<1$ in SMCE (by the assumption $\beta<1+\theta$ ), it follows that (8) cannot hold in SMCE, contradicting that $w_{t} / p_{t}=\gamma$ supports SMCE.

Now suppose $w_{t} / p_{t} \in[1, \gamma)$. The CIA constraint in the labor market will be binding for agent 2 , so we can substitute $L_{t}^{d}=\left(M_{2, t}+\theta M_{t}\right) / w_{t}$ into the objective function of $\left(P 2^{\prime}\right)$ to obtain

$$
\max \sum_{t=0}^{\infty} \beta^{t} U\left(\gamma \frac{M_{2, t}+\theta M_{t}}{w_{t}}+\frac{1}{p_{t}}\left(M_{2, t}+\theta M_{t}-M_{2, t+1}\right)\right) .
$$

In this case, the Euler equation, associated with control $\left(1 / p_{t}\right) M_{2, t+1}$, is given by

$$
U^{\prime}\left(c_{2, t}\right)=\frac{p_{t} \beta \gamma}{w_{t+1}} U^{\prime}\left(c_{2, t+1}\right), \text { for all } t .
$$

At a stationary equilibrium, $c_{2, t+1}=c_{2, t}$ must hold for all $t$. Since $U^{\prime}()>$.0 , it then follows that $w_{t+1} / p_{t}=\beta \gamma$ in SMCE. Using $w_{t+1}=(1+\theta) w_{t}$, we obtain $w_{t} / p_{t}=\beta \gamma /(1+\theta)$. Note that $w_{t} / p_{t}<\gamma$ in SMCE, since $\beta<1+\theta$ by assumption.

If $\beta \gamma>1+\theta$ then $w_{t} / p_{t}>1$ and $L_{t}^{s}=L_{t}^{d}=\bar{L}$, implying that $w_{t}=\left(M_{2, t}+\theta M_{t}\right) / \bar{L}=M_{t+1} / \bar{L}$ for all $t$. It then follows that $p_{t}=$ $(1+\theta) w_{t} /(\beta \gamma)=M_{t+2} /(\beta \gamma \bar{L})$ for all $t$, and $q_{t}^{s}=q_{t}^{d}=\left(M_{2, t}+\theta M_{t}\right) / p_{t}=$ $\beta \gamma \bar{L} /(1+\theta)$ for all $t$.

If $\beta \gamma=1+\theta$ then $L_{t}^{s} \in[0, \bar{L}]$. So, for any wage sequence $w_{t}=(1+\theta)^{t} \bar{w}$ with $\bar{w} \in[(1+\theta) M / \bar{L}, \infty)$ the labor market will be in equilibrium with $L_{t}^{d}=L_{t}^{s}=M_{t+1} / w_{t}=(1+\theta) M / \bar{w}$ for all $t$. The apple price will be $p_{t}=(1+\theta)^{t} \bar{w}$ and the goods market will be in equilibrium with $q_{t}^{s}=q_{t}^{d}=$ $M_{t+1} / w_{t}=(1+\theta) M / \bar{w}$ for all $t$. 
Finally, note that the transversality condition for agent 2 is satisfied, since we have

$$
\begin{aligned}
\lim _{t \rightarrow \infty} \beta^{t} \frac{\gamma}{w_{t}} U^{\prime}\left(c_{2, t}\right) & =\lim _{t \rightarrow \infty} \beta^{t} \frac{\gamma L_{t}^{d}}{M_{t+1}} U^{\prime}\left(\left(1-\frac{\beta}{1+\theta}\right) \gamma L_{t}^{d}\right) \\
& =\lim _{t \rightarrow \infty}\left(\frac{\beta}{1+\theta}\right)^{t} \frac{\gamma L_{t}^{d}}{(1+\theta) M} U^{\prime}\left(\left(1-\frac{\beta}{1+\theta}\right) \gamma L_{t}^{d}\right) \\
& =0,
\end{aligned}
$$

using the fact that in SMCE $L_{t+1}^{d}=L_{t}^{d} \leq \bar{L}$ for all $t$ and the assumption that $\beta<1+\theta$.

The Euler equation (9) together with the transversality condition above verifies that agent 2 is maximized at the described equilibrium. One can easily check that the inequality constraints in both $(P 1)$ and $(P 2)$ are also satisfied, which completes the proof.

The most striking feature of this result is that in the whole class of SMCE proposed by $(3)-(7)$ the real wage rate $\beta \gamma /(1+\theta)$ is below the marginal product of labor $\gamma$ in the superior plant. So, both agent 1 (the owner of the inferior technology, and de facto the worker) and agent 2 (the owner of the superior technology, and de facto the enterpreneur) are better off in the monetary equilibria relative to an autarky. This result, however, rests upon the assumption that the contracts on apples are not enforceable. In an economy where commodity contracts are enforceable, the entrepreneur would be left with zero profits, since competition under the absence of finance constraints would equalize the real wage rate with the marginal (and in this case also the average) product of labor.

Another observation is that the apple price in the equilibrium is decreasing in the marginal product of labor $\gamma$ and in the subjective discount rate $\beta$ and increasing in the inflation rate. That is, in societies that are more patient or more productive, workers buy the apple at a lower price and consume more of it. Similarly, inflation is observed to affect the workers welfare adversely by reducing equilibrium real wages. If inflation is too high or if there is too much discounting or insufficient productivity, then the monetary equilibrium may break-down.

A final observation is about the neutrality of the initial level of money stock. In situations where $\beta \gamma /(1+\theta)>1$, so that $w_{t} / p_{t}>1$, money is trivially seen to be neutral. However, in the case of $w_{t} / p_{t}=1$, labor supply becomes infinitely elastic, and hence the nature of the stationary monetary competitive equilibria allows for situations where money is not neutral as well as situations where it is. That is, when the nominal wages $w_{t}$ are exogeneously determined in the interval of $\left[M_{2, t+1} / \bar{L}, \infty\right)$, satisfying $w_{t+1} / w_{t}=(1+\theta)$, an increase in the initial money stock, $M$, in the economy gives rise to an equal amount of increase in labor transacted and hence quantity of apples produced, which can be seen from equations (5) and (6). 
But, since the simple economic environment that we consider in this paper does not identify an equilibrium selection mechanism for nominal wage determination when $w_{t} / p_{t}=1$, one may equally be justified in claiming that nominal wages and prices move together with money holdings, leaving the real side of the economy unaffected. So, we have a situation of indeterminacy, which certainly involves an extreme yet an interesting possibility for non-neutrality of money in the context of a model with maximizing agents, perfect foresight and market clearing.

\section{Conclusions}

In this paper, we examined a very simple model in which cash-in-advance requirements for production affect the functional distribution of income. We introduced some heterogeneity by allowing for two types of representative agents, a worker type and an entrepreneur type. In order to attain the stationarity of equilibrium, we distributed all the initial fiat money to the entrepreneurs. As a consequence, these agents are observed to become employers in equilibrium and to enjoy higher profits than what would prevail in an Arrow-Debreu economy.

When there is money growth in the form of lump-sum transfers to the enterpreneurs, the equilibrium real wage is observed to be adversely affected by the resulting inflation rate. Similarly, the real wage is adversely and favorably affected by the subjective discount factor and the productivity of labor respectively. If these three factors tend to draw the equilibrium below the reservation real wage of the workers, the monetary equilibrium breaks down and an inefficient situation of autarky may prevail. Such a case would be observed, for example, under very high inflation rates.

When there is deflation through lump-sum taxation of the entrepreneurs, however, the real wages become higher. And in fact under the optimal money supply rule, the Arrow-Debreu equilibrium is restored. This rule, which consists of equating the rate of monetary contraction with the subjective discount rate (i.e. $\theta=\beta-1$ ), was suggested by Friedman (1969) and was later studied in the context of cash-in-advance economies where good markets open first, but leisure enters the utility function (see, for example, the survey by Woodford, 1990). Here we show that this rule is also applicable in economies where factor markets open first.

We also observe an indeterminacy of equilibria under very specific parameter values. This corresponds to the case where real wage is as low as the reservation wage of workers, so that the labor supply is infinitely elastic. This allows for situations where unexpected jumps in the nominal money supply may not be neutral, and may favorably affect total output.

The results of the paper are sensitive to the sequencing of markets. If we were to distribute all of the initial money to workers, and to let the goods market open first, the Arrow-Debreu allocations would be obtained. However, we would like to argue that the "factor markets first" scenario is 
more realistic, since sales of goods before production takes place (via forward commodity contracts) are observed very rarely in real life economies.

\section{References}

Arrow, K.: The role of securities in the optimal allocation of risk-bearing. Review of Economic Studies 31, 91-96 (1964)

Baş̧ı, E.: Markets as institutions. Unpublished Ph.D. dissertation, Bilkent University, Department of Economics (1995)

Clower, R.W.: A reconsideration of the microfoundations of monetary theory. Western Economic Journal 6, 1-8 (1967)

Debreu, G.: Theory of value. New York: Wiley (1959)

Friedman, M.: The optimum quantity of money and other essays. Chicago: Aldine (1969)

Fuerst, T.S.: Liquidity, loanable funds and real activity. Journal of Monetary Economics 29, 3-24 (1992)

Lucas, R.E., Jr.: Equilibrium in a pure currency economy. Economic Inquiry 18, 203-20 (1980)

Lucas, R.E., Jr.: Money in a theory of finance. Carnegie-Rochester Conference Series on Public Policy 21, 9-46 (1984)

Lucas, R.E., Jr.: Liquidity and interest rates. Journal of Economic Theory 50, 237-64 (1990)

Lucas, R.E., Jr. and Stokey, N.L.: Optimal fiscal and monetary policy in an economy without capital. Journal of Monetary Economics 12, 55-93 (1983)

Lucas, R.E., Jr. and Stokey, N.L.: Money and interest in a cash-in-advance economy. Econometrica 55, 491-513 (1987)

Stokey, N.L. and Lucas, R.E., Jr. with E.C Prescott: Recursive methods in economic dynamics. Cambridge: Harvard University Press (1989)

Woodford, M.: The optimum quantity of money. In: Friedman, B.M., Hahn F.H. (eds.) Handbook of monetary economics. Amsterdam, New York: North-Holland (1990) 